\title{
Effectiveness of percutaneous flexor tenotomies for the management and prevention of recurrence of diabetic toe ulcers: a systematic review
}

Jennifer E. Scott, Gordon J. Hendry ${ }^{*}$ and John Locke

\begin{abstract}
Background: Diabetic toe ulcers are a potentially devastating complication of diabetes. In recent years, the percutaneous flexor tenotomy procedure for the correction of flexible claw and hammer-toe contraction deformities has been proposed as a safe and effective technique for facilitating the healing of toe-deformity related diabetic ulcers. The aim of this review is to critically appraise the evidence for the effectiveness of this surgical procedure in achieving ulcer healing, prevention of re-ulceration, and to summarise the rate of post-operative complications.

Method: A search of medical databases, was performed to locate relevant literature. Titles were screened prior to abstract and full text review to identify articles relevant to the research question. Search terms included truncations of "tenotomy", "toe", "hallux", "digit", "diabetes" and "ulcer". Peer reviewed primary research study designs specified as suitable for systematic reviews by the Centre for Reviews and Dissemination were included. Studies were excluded if they used a concurrent secondary procedure or included non-diabetic patients without reporting outcomes separately. Included studies were appraised for quality using the Methodological Index for Non-Randomised Studies tool. Levels of evidence were subsequently assigned to each outcome of interest (healing rate and prevention of re-ulceration).

Results: From a total search yield of 42 articles, 5 eligible studies (all case series designs) were identified for inclusion. Included studies were of low-to-moderate methodological quality when assessed using the MINORS tool. A total of 250 flexor tenotomy procedures were performed in a total of 163 patients. Included studies generally reported good healing rates (92-100\% within 2 months) post-op follow-up), relatively few recurrences (0-18\% at 22 months median post-op follow-up), and low incidences of infection or new deformity. Transfer ulcers developing on adjacent areas as a result of shifted pressure were reported by several authors.

The validity of these results is undermined by methodological limitations inherent to case series designs such as a lack of control groups, non-randomised designs, as well as inconsistent reporting of post-intervention follow-up periods.

There was level 4 evidence for the flexor tenotomy procedure in facilitating ulcer healing and preventing re-ulceration.

Conclusion: More definitive research evidence is needed in this area to determine whether or not the flexor tenotomy is a safe and effective treatment option for people with, or at risk of developing diabetic toe ulcers. Whilst the available literature reports that the procedure may be associated with high healing rates, relatively low recurrence rates and low incidences of post-op complications, methodological limitations restrict the value of these findings.
\end{abstract}

Keywords: Flexor tenotomy, Toe ulcer, Diabetes, Ulceration, Plantar pressure, Toe deformity

*Correspondence: gordon.hendry@gcu.ac.uk

School of Health and Life Sciences / Institute for Applied Health Research,

Glasgow Caledonian University, Cowcaddens Road, Glasgow G4 OBA, UK

(c) 2016 The Author(s). Open Access This article is distributed under the terms of the Creative Commons Attribution 4.0 International License (http://creativecommons.org/licenses/by/4.0/), which permits unrestricted use, distribution, and reproduction in any medium, provided you give appropriate credit to the original author(s) and the source, provide a link to the Creative Commons license, and indicate if changes were made. The Creative Commons Public Domain Dedication waiver (http://creativecommons.org/publicdomain/zero/1.0/) applies to the data made available in this article, unless otherwise stated. 


\section{Background}

Foot ulceration can be a devastating complication of diabetes. The dorsum, apices and plantar aspects of the toes are particularly vulnerable locations for diabetic foot ulcers, with studies showing ulcers occurring on toes 1-5 accounting for between 43 and $55.5 \%$ of all foot ulcers $[1,2]$. Whilst digital ulcers tend to be smaller and heal faster than forefoot, mid-foot or heel ulcers [3], they may be an important prognostic indicator given that they may precede up to $63.9 \%$ of diabetic limb amputations [4], the corollary being that timely resolution and prevention of toe ulceration is crucial to avoid poor long-term outcomes.

Toe deformities such as 'hammer' and 'claw' toes have been associated with the development of diabetic foot ulceration, particularly in the presence of complicating factors such as neuropathy and peripheral vascular disease [5]. During weight-bearing or gait, insensate and deformed toes may be subject to increased pressures and shear stresses, which can result in callous formation, tissue trauma, and ultimately ulceration [6].

Off-loading pressure from ulcer sites is considered to be an important treatment goal for promoting healing and preventing the ulcer from recurring [7] Historically the conventional approach to pressure offloading has been conservative through debridement of superficial skin lesions (corns, callus), deflective padding, insoles, and/or therapeutic footwear $[6,8,9]$. However robust evidence of the efficacy of such interventions is lacking and what does exist is confounded by poor patient adherence. Indeed, patient adherence to wearing removable offloading devices such as pressure relieving footwear has been reported as being particularly problematic [10].

Researchers have suggested that certain surgical interventions can reduce the risk of foot ulcer recurrence in patients with diabetes and peripheral neuropathy [11]. Minimally-invasive surgical procedures may reduce infection and healing rates [12]. The flexor tenotomy procedure is advocated for flexible toe deformities [13] and can be performed on both the hallux and lesser toes. During this operation, the flexor digitorum/hallucis longus tendon is transected under local anaesthetic through a single plantar incision [14], with some surgeons also choosing to release the flexor digitorum/hallucis brevis tendon [15]. The therapeutic aim is to release the flexor digitorum brevis/longus tendon contraction, allowing the toe to adopt a straighter position in order to alleviate the focal pressure on areas of ulceration, in particular the toe apices. The procedure is generally conducted on an outpatient basis.

A systematic review [8] published in 2009 sought to establish whether or not the flexor tenotomy procedure was safe and effective for the treatment of toe ulcers in diabetic patients. This review concerned neuropathic
DFUs and was limited to the evaluation of two caseseries studies $[16,17]$ which were deemed to be of poor methodological design, but which indicated that the procedure may result in healing of digital ulcers with a low incidence of complications [8]. Since this review several new studies on this procedure have been published, widening the body of evidence on this procedure, and necessitating an updated review of the available literature. Accordingly, the aim of this review is to critically evaluate the available literature to establish if there is sufficient evidence to demonstrate that the flexor tenotomy for diabetic ulcers on the apices of the hallux and lesser toes is 1) effective in achieving ulcer healing, 2) effective in preventing recurrence of ulcers, and 3) to summarise the rates of post-operative complications.

\section{Methods}

\section{Search strategy}

During 1st-30th September 2015, Pubmed and EBSCO Host (incorporating AMed, CINAHL, Health Source and MEDLINE) databases, as well as the Cochrane Library and World Health Organisation International Clinical Trials Registry were searched by the first author for relevant literature. The reference lists of relevant articles were also searched by hand.

The search terms, truncation and Boolean operators used to search the databases are outlined in Table 1 . Given that the flexor tenotomy is an emerging surgical approach, no filters were applied (i.e. all fields were searched) in order to ensure the widest possible return of results. The earliest reference found for the use of the procedure in toe deformities in any patient population dated to 1975 [18]. All literature from this year onwards was included in the search.

\section{Inclusion and exclusion criteria}

Forty-two titles and abstracts were screened by the first author to eliminate duplicates and obviously irrelevant articles. The first author then accessed the full texts of the remaining 13 studies and reviewed them against the inclusion and exclusion criteria to identify articles relevant to the research question. The process of selecting the included papers is summarised in Fig. 1, with the full list of papers excluded included in an additional file [See Additional file 1].

Peer reviewed primary research study designs specified as suitable for systematic reviews by the Centre for Reviews and Dissemination (CRD) [19] were included. These comprise randomised controlled trials, quasiexperimental studies and observational studies. Studies reporting outcomes for the hallux and/or lesser toes were included. As Diabetic Foot Ulcers (DFUs) may be multifactorial, diabetic patient groups with or without neuropathy or peripheral arterial disease were included. 
Table 1 Literature Search Terms

\begin{tabular}{ll}
\hline Terms & Rationale \\
\hline 1. Tenotom* AND & 1. No alternative synonym for tenotomy was located. \\
2. (toe* OR hallux OR digit*) AND & 2. Tenotomies are performed on many joints e.g. knee and shoulder. Specific anatomical location is required. \\
3. (diabet* OR ulcer*) & 3. 'Diabetes' and 'Ulcer' keywords ensure relevance to research population.
\end{tabular}

*representes the use of truncation

Studies were excluded if they 1) used a concurrent secondary procedure (e.g. osteotomy), 2) were study designs not specified in CRD evidence hierarchy [19] (e.g. reviews, meta-analysis, single-case studies) or 3) Included nondiabetic patients without reporting outcomes separately.

\section{Data extraction}

Data extraction was performed by the first author, and all queries were discussed and resolved by the supervisory team in regular meetings. Data concerning sample size, participant age, gender, diabetes and ulcer characteristics, surgical intervention and surgical outcomes were extracted from the studies directly into a Microsoft Word table using headings relevant to the research question (Table 2, Table 3).

\section{Quality appraisal and evidence grading}

The quality of the selected studies was assessed using the Methodological Index for Non-Randomised Studies (MINORS) tool [20] by two independent reviewers (JS under supervision from JL, and GJH respectively). Discrepancies in scoring were moderated by a third reviewer (JL) and the final scores agreed upon by the reviewer team. The MINORS tool is a validated instrument specifically designed to overcome inherent difficulties in evaluating surgical studies where randomisation, control groups and blinding are challenging to achieve [21]. The MINORS evaluation allowed notable similarities and differences in the selected studies to be highlighted and synthesised [See Additional file 2]. Following the analysis and synthesis of the extracted data, an evidence rating was assigned according to Oxford Centre for Evidence-based Medicine evidence grading system [22].

\section{Results}

\section{Search yield}

Five primary research papers met the criteria for appraisal in this review; Kearney et al. [23], Laborde [17], Rasmussen et al. [15], Tamir et al. [24] and Van Netten et al. [25].

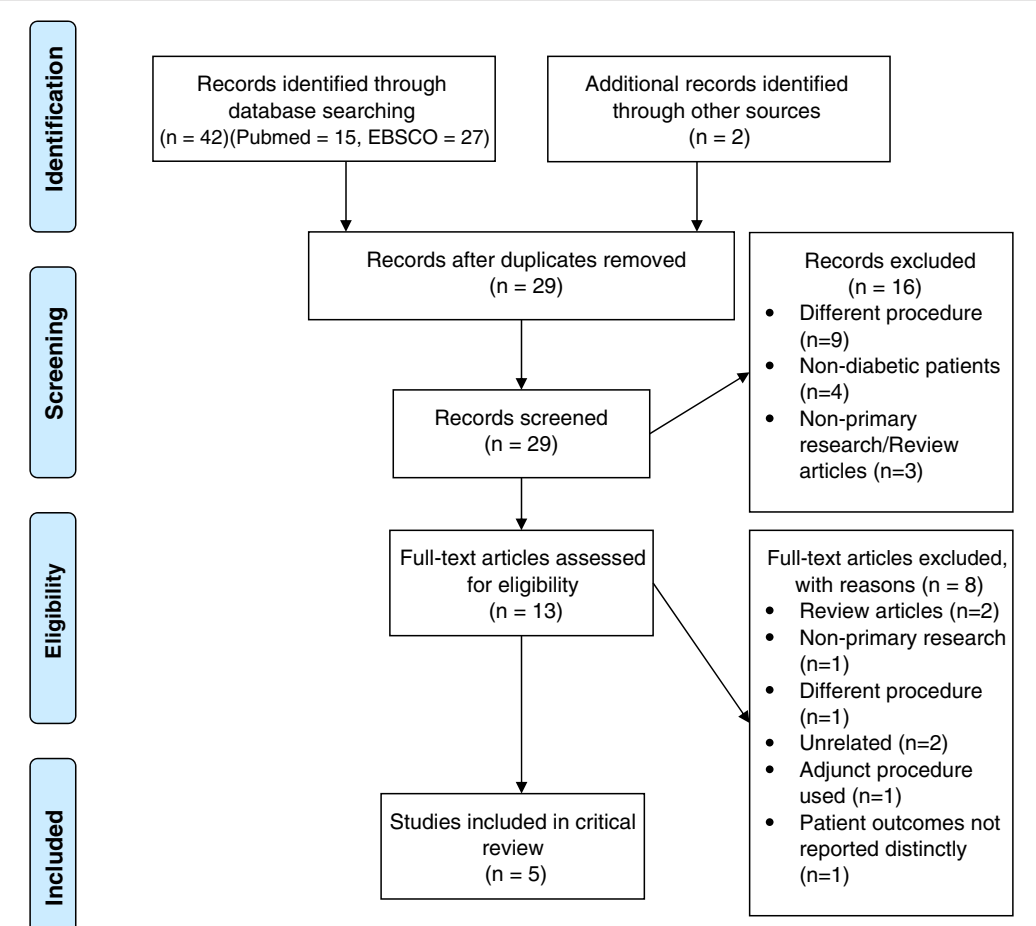

Fig. 1 PRISMA Diagram (Adapted from Moher et al. [30]) 
Table 2 Literature Review - Study Characteristics

\begin{tabular}{|c|c|c|c|c|c|}
\hline & Kearney et al. [23] & Laborde [17] & Rasmussen et al. [15] & Tamir et al. [24] & Van Netten et al. [25] \\
\hline Patients (No.) & 48 & 14 & 16 & 55 & 30 \\
\hline Procedures (No.) & 58 & 24 & 27 & 103 & 38 \\
\hline \multirow[t]{2}{*}{ Age range (Years) } & \multirow[t]{2}{*}{ • Mean $68.1 \pm 2.3$} & $\cdot 40-81$ & $\cdot 37-91$ & • 48-89 & $\cdot 42-93$ \\
\hline & & • Mean 55 & - Mean 62.8 & - Mean 65 & - Mean $69 \pm 12$ \\
\hline Gender & - M:11, F:37 & • M: 7 F: 11 & $\begin{array}{l}\text { - Insufficiently reported: prophylactic and } \\
\text { ulcerated patients reported together }\end{array}$ & - Not reported & • M: 17, F:16 \\
\hline Diabetes duration & - Not reported & - Not reported & $\begin{array}{l}\text { - Insufficiently reported: prophylactic and } \\
\text { ulcerated patients reported together }\end{array}$ & $\begin{array}{l}\text { - Insufficiently reported - patients receiving } \\
\text { different interventions reported together }\end{array}$ & - Not reported \\
\hline $\mathrm{HbA} 1 \mathrm{C}$ & $\cdot 7.3 \pm 1.4$ & - Not reported & $\begin{array}{l}\text { - Insufficiently reported: prophylactic and } \\
\text { ulcerated patients reported together }\end{array}$ & $\begin{array}{l}\text { - Insufficiently reported - patients receiving } \\
\text { different interventions reported together }\end{array}$ & - Not reported \\
\hline \multirow[t]{2}{*}{ Inclusion criteria } & - Diabetes & \multirow[t]{2}{*}{ - Not reported } & \multirow[t]{2}{*}{ - Not reported } & \multirow[t]{2}{*}{ - Not reported } & \multirow[t]{2}{*}{ - Not reported } \\
\hline & - Distal toe ulceration & & & & \\
\hline \multirow[t]{3}{*}{ Exclusion criteria } & - Healed ulcer & \multirow[t]{3}{*}{ - Grade $4 / 5$ ulcers $^{b}$} & \multirow[t]{3}{*}{ - Not reported } & \multirow{3}{*}{$\begin{array}{l}\text { - ABPI below } 0.5 / \text { flat pulse volume } \\
\text { at ankle } \\
\text { - Cellulitis }\end{array}$} & \multirow[t]{3}{*}{ - Not reported } \\
\hline & \multirow[t]{2}{*}{ - Adjunct procedures } & & & & \\
\hline & & & & & \\
\hline \multirow[t]{2}{*}{$\begin{array}{l}\text { Pre-selection assessments } \\
\text { (\% of patients with condition) }\end{array}$} & $\begin{array}{l}\text { - Neuropathy: mono-filament/ } \\
\text { biothesiometer (100\%) }\end{array}$ & $\begin{array}{l}\text { • Neuropathy: mono- } \\
\text { filament (100\%) }\end{array}$ & $\begin{array}{l}\text { - Neuropathy: monofilament/ } \\
\text { biothesiometer (100\%) }\end{array}$ & $\begin{array}{l}\text { - Neuropathy: Assessment and patient } \\
\text { characteristics not reported. }\end{array}$ & $\begin{array}{l}\text { - Neuropathy: } \\
\text { monofilament (100\%) }\end{array}$ \\
\hline & • PAD: absent pulses (36.2 \%) & $\begin{array}{l}\text { - Poor vascular status: } \\
\text { absent pulses (14\%) }\end{array}$ & $\begin{array}{l}\text { - Poor arterial perfusion: Pulses/ankle } \\
\text { blood pressure (18\%) }\end{array}$ & - Vascular status: ABPI (\% not reported) & $\begin{array}{l}\text { - PAD: absent } \\
\text { pulses/Doppler (0 \%) }\end{array}$ \\
\hline \multirow{3}{*}{$\begin{array}{l}\text { Ulcer grades }- \text { No. (\% of } \\
\text { ulcers) }\end{array}$} & \multirow[t]{3}{*}{ - Not reported } & $\cdot 1^{\mathrm{b}}-11(46 \%)$ & $\cdot 1^{\mathrm{a}}-23(85 \%)$ & $\cdot 0^{\mathrm{a}}-25(24 \%)$ & $\cdot 1^{a}-20(53 \%)$ \\
\hline & & $\cdot 2^{\mathrm{b}}-5(21 \%)$ & $\cdot 2^{\mathrm{a}}-1(4 \%)$ & $\cdot 1^{a}-73(71 \%)$ & $\cdot 2^{\mathrm{a}}-0(0 \%)$ \\
\hline & & $\cdot 3^{b}-8(33 \%)$ & $\cdot 3^{a}-3(11 \%)$ & $\cdot 2 / 3^{a}-5(5 \%)$ & $\cdot 3^{a}-18(47 \%)$ \\
\hline \multirow[t]{2}{*}{ Ulcer duration } & \multirow[t]{2}{*}{ - Not reported } & $\cdot 1$ month -5 years & - Range 1-48 weeks & • Range: 1 - 156 Weeks & - 9 - 525 days \\
\hline & & - Average: 10 months & - Median: 15 weeks & - Mean: 33 weeks & - Mean: 96 days \\
\hline \multirow[t]{5}{*}{ Digit tenotomised } & \multirow{5}{*}{$\begin{array}{l}\text { - Not specified - only FDL } \\
\text { transected, therefore } \\
\text { assumed to be digits 2-5 }\end{array}$} & · Hallux - 14 & · Hallux - 15 & $\cdot$ Hallux - 16 & - Hallux - 12 \\
\hline & & $\cdot 2-7$ & $\cdot 2-10$ & $\cdot 2-31$ & $\cdot 2-15$ \\
\hline & & $\cdot 3-2$ & $\cdot 3-2$ & $\cdot 3-37$ & $\cdot 3-11$ \\
\hline & & $\cdot 4-0$ & $\cdot 4-0$ & $\cdot 4-16$ & $\cdot 4-0$ \\
\hline & & $\cdot 5-1$ & $\cdot 5-0$ & $\cdot 5-3$ & $\cdot 5-0$ \\
\hline Incision location & Distal phalanx & $\begin{array}{l}\text { Proximal portion of } \\
\text { proximal phalanx }\end{array}$ & $1 \mathrm{~cm}$ proximal to the web fold & Mid-portion of proximal phalanx & $\begin{array}{l}\text { Mid-portion of } \\
\text { proximal phalanx }\end{array}$ \\
\hline \multirow[t]{3}{*}{ Tendons transected } & \multirow[t]{3}{*}{ - FDL - 58 toes } & • FDL \& FDB - & - FDL \& FDB - & • FDL - 87 Toes & $\cdot$ FDL - 26 Toes \\
\hline & & $\cdot 10$ toe & • 12 Toes & \multirow[t]{2}{*}{ • FHL - 16 Toes } & \multirow[t]{2}{*}{ • FHL - 12 Toes } \\
\hline & & • FHL - 14 Toes & - FHL \& FHB - 15 Toes & & \\
\hline
\end{tabular}


Table 2 Literature Review - Study Characteristics (Continued)

\begin{tabular}{|c|c|c|c|c|c|}
\hline \multirow[t]{2}{*}{ Post-op offloading } & - Immediate weightbearing & • Full weightbearing & -2-3 days post-op hosp. immobilization & \multirow[t]{2}{*}{ - Not reported } & \multirow{2}{*}{$\begin{array}{l}\text { - } 24 \mathrm{~h} \text { offloading plus } \\
\text { pressure bandage }\end{array}$} \\
\hline & - Rigid soled sandals & $\begin{array}{l}\text { - Post-op shoes/sandals/ } \\
\text { extra depth shoe }\end{array}$ & - Rocker bottom sandals + soft insoles & & \\
\hline Return appointment & Not reported & $\begin{array}{l}3-5 \text { days then weekly } \\
\text { until healed }\end{array}$ & 1 weeks then as required until healed & 1 week then regularly until healed & 1 week then regularly \\
\hline \multirow[t]{3}{*}{ Follow-up period (months) } & \multirow[t]{3}{*}{ - Mean: 28} & \multirow[t]{2}{*}{$\cdot 20-64$} & \multirow[t]{2}{*}{$\cdot 2-48$} & - Minimum: 5 & $\cdot 11-60$ \\
\hline & & & & - Interquartile range:16-29 & - Mean: $23 \pm 11$ \\
\hline & & - Average: 36 & - Median: 31 & - Median: 22 & \\
\hline
\end{tabular}

KEY: No. Number, ABPI Ankle Brachial Pressure Index, PAD Peripheral Arterial Disease, FDL Flexor Digitorum Longus, FDB Flexor Digitorum Brevis, FHL Flexor Hallucis Longus, FHB Flexor Hallucis Brevis, ${ }^{a}$ Ulcer Grades on Texas Scale [26], bUlcer grades on Wagner's Scale [26]

NOTE: Data reported in the original studies on non-diabetic patients [17], non-Flexor Tenotomy procedures [24] and prophylactic procedures [15, 25] have been omitted from this table due to irrelevance to the research question 
Table 3 Literature Review - Results

\begin{tabular}{|c|c|c|c|c|c|}
\hline & Kearney et al. [23] & Laborde [17] & Rasmussen et al. [15] & Tamir et al. [24] & Van Netten et al. [25] \\
\hline $\begin{array}{l}\text { Ulcers Healed } \\
\text { (\% of ulcers) }\end{array}$ & $98.3 \%$ & $100 \%$ & $93 \%$ & $98 \%$ & $92 \%$ \\
\hline \multirow[t]{2}{*}{ Healing Time } & \multirow[t]{2}{*}{ - $40 \pm 52$ days } & \multirow[t]{2}{*}{ - Under 2 months } & $\cdot$ - 7-224 days & \multirow{2}{*}{$\begin{array}{l}\text { - } 98 \% \text { wound closure } \\
\text { within } 4 \text { weeks }\end{array}$} & • 4-154 days \\
\hline & & & - Median: 21 days & & - Mean $22 \pm 26$ days \\
\hline \multirow{2}{*}{$\begin{array}{l}\text { Recurrence } \\
\text { (\% of ulcers) }\end{array}$} & $\cdot 12 \%$ & • $8 \%$ & • $11 \%$ & \multirow[t]{2}{*}{$.0 \%$} & • $18 \%$ : \\
\hline & - 7 lesser toe ulcers & - 2 hallux ulcers & - 3 ulcers - not specified & & - 4 lesser toes, 3 first toes \\
\hline Time to recur & $13.9 \pm 15.2$ months & 45-48months & Not reported & Not applicable & Not Reported \\
\hline Infections & 2 Ulcers (3 \%) & $0 \%$ & $0 \%$ & 1 Patient (2\%) & $0 \%$ \\
\hline \multirow[t]{4}{*}{ Complications } & \multirow{4}{*}{$\begin{array}{l}\text { - } 1 \text { Amputation: ulcer } \\
\text { non-healing due to } \\
\text { pre-existing } \\
\text { osteomyelits }\end{array}$} & \multirow[t]{4}{*}{$\begin{array}{l}\text { - No infections or new } \\
\text { deformities occurred }\end{array}$} & \multirow{4}{*}{$\begin{array}{l}\cdot 2 \text { transfer lesions } \\
\text { ( } 7 \% \text { of procedures) } \\
\text { developed } 5 \text { and } 7 \\
\text { months after surgery }\end{array}$} & $\begin{array}{l}\text { - } 2 \text { ulcers non-healing due } \\
\text { to insufficient offloading/ } \\
\text { arterial insufficiency }\end{array}$ & $\begin{array}{l}\text { - } 3 \text { Amputations: ulcers non- } \\
\text { healing due to pre-existing } \\
\text { infection to bone }\end{array}$ \\
\hline & & & & $\begin{array}{l}\text { - } 9 \text { Transfer lesions within } \\
8 \text { weeks of surgery } \\
\text { (9\% of procedures) }\end{array}$ & $\begin{array}{l}\text { - } 8 \text { shifted (transfer) ulcers } \\
\text { ( } 21 \% \text { of procedures) }\end{array}$ \\
\hline & & & & - 3 Plantar skin ruptures & \multirow{2}{*}{$\begin{array}{l}\text { - Dorsiflexion of the } \\
\text { Metatarso-phalangeal joint. }\end{array}$} \\
\hline & & & & - 1 Pain & \\
\hline
\end{tabular}

\section{Participant characteristics}

The numbers of non-prophylactic procedures performed in the 5 selected studies totalled 250, ranging from 24 in Laborde [17] to 103 in Tamir et al. [24]. The total patient numbers across the studies totalled 163 (Range 14-55) as several patients had multiple tenotomies. All authors obtained patient, procedure and outcome data from retrospective review of medical charts and reported participant characteristics using descriptive statistics to varying levels of detail (Table 2, Table 3). Laborde [17] and van Netten et al. [25] provided relatively comprehensive tables on individual patient characteristics, outcomes and complications, facilitating a more detailed evaluation of their findings.

\section{Ulcer characteristics}

All studies, with the exception of Kearney et al. [23], obtained baseline ulcer characteristics using the University of Texas (UT) or Wagner ulcer classification systems [26]. Tamir et al. [24] performed the majority of procedures on low-complexity ulcers, with only $5 \%$ of lesions classified as UT Grade 2 or 3 (penetrating to tendon/ capsule or bone/joint). UT Grade 2 and 3 ulcers accounted for 54, 15 and $47 \%$ of procedures in Laborde [17], Rasmussen et al. [15] and van Netten et al. [25] respectively. All ulcers were located on the distal apex of the toe, and all authors operated on both the hallux and lesser toes, with the exception of Kearney et al. [23] who reported no hallux procedures.

\section{Intervention}

All surgeons performed the procedure using a single percutaneous incision, with variations in the tendons cut and the location of the incision shown in Table 2. All authors chose to release flexor hallucis/digitorum Longus (FHL/FDL), however Laborde [17] and Rasmussen et al. [15] also chose to transect flexor hallucis/digitorum Brevis (FHB/FDB).

\section{Post-operative care}

When reported, post-operative measures varied. Several authors $[15,17,23]$ reported prescribing offloading footwear after surgery. Rasmussen et al. [15] appear to have employed a particularly rigorous post-operative regime, mandating hospital admission, 2-3 days of immobilisation and prophylactic antibiotics.

\section{Healing, recurrence and infection}

All studies provided descriptive statistics reporting high healing rates (92-100 \% at up to 227 days) and few recurrences (0-18\% at 22 months median follow-up) (Table 3). Van Netten et al. [25] found a statistically significant association between UT ulcer classification and healing time $(p=0.042)$, with more complex ulcers taking longer to heal. In this study, healing was not achieved in three patients, all of whom had UT grade 3B ulcers (infected wound, penetrating to bone) and subsequently underwent digital amputation. Van Netten et al. [25] noted that all seven recurrences in their study occurred in toes with infection penetrating to bone (UT Grade 3B ulcers), while Laborde [17] noted that both recurrences in his study occurred following ulcers probing to tendon (Wagner's Grade 2 ulcers) [26].

\section{Follow-up}

All studies reported a mean or median follow-up between 22 and 36 months, however the minimum follow-up periods reported in Rasmussen et al. [15] and Tamir et al. 
[24] were two and five months respectively. Only Laborde [17] provided any information on the follow-up protocol, reporting that 12 patients were assessed in person and 6 by telephone.

\section{Complications}

The studies report relatively low incidences of infection or new deformity (Table 3). Transfer ulcers (ulcers developing on adjacent areas as a result of shifted pressure) were reported by several authors. Rasmussen et al. [15] recorded two transfer ulcers and Tamir et al. [24] reported nine. Of the 38 tenotomies performed by Van Netten et al. [25], 8 were performed on toes that had developed transfer ulcers from an adjacent tenotomised digit. It could be argued that the 8 tenotomies performed on toes following a prior procedure were not in fact classic diabetic foot ulcers, and were instead sequelae of surgery and should have been discounted from the cases reported in their article. The authors report that these eight 'shifted' ulcers healed and did not recur, nor result in any further transfer lesions.

\section{Quality and evidence grading}

The studies reviewed scored between 5 and 8 out of an available score of 16, indicating low methodological quality [see Additional file 2]. There is level 4 evidence to support the statement that flexor tenotomy is effective for the healing of and the prevention of digital ulcers in diabetes.

\section{Discussion}

Healing diabetic toe ulcers can be a challenging and protracted process with high recurrence rates, negatively affecting the patients' quality of life and potentially leading to amputation. It is therefore highly important to establish effective interventions to reduce these negative consequences. Overall, the studies included in this review describe promising results following flexor tenotomy with regard to ulcer healing and recurrence rates: an average of $96.3 \%$ of ulcers healed, and an average of $9.8 \%$ recurred. It would thus appear that the Flexor Tenotomy procedure may be an effective intervention for healing and reducing recurrence of diabetic toe ulcers. The procedure also appears to have a low incidence of complications, with the exception of transfer ulceration, which is not discussed in depth in the studies.

While reported outcomes are encouraging, several aspects of the studies deserve further discussion. All five publications described in this review are retrospective case series, and are therefore vulnerable to bias. The absence of randomisation to a control group means that any changes observed are the result of an uncontrolled pre-post analysis instead of a comparative analysis with control subjects who receive an alternative treatment such as current standard conservative care. Furthermore, the retrospective nature of the data collection introduces the potential for selection bias; indeed, none of the studies provide clear outlines of their sampling processes. The small sample size of the studies poses a further difficulty in generalising the findings.

Differences in surgical technique, specifically tendon choice for resection, may introduce significant heterogeneity between studies, impairing comparability and assessment of the merits of each technique. Rasmussen et al. [15] prefer to sever both FDL/FHL and FDB/FHB tendons to provide maximum relaxation of the flexion deformity, whereas Van Netten et al. [25] imply that severing both tendons is not without complications. They report that inadvertently severing FHB in one of their subjects may have accounted for over-extension of one toe that lead to a dorsal transfer ulcer forming. Laborde [17] attributes the recurrence of three first toe ulcers in his study to a failure to transect FHB.

Studies have shown that, certain types of post-operative footwear can reduce plantar pressures in the forefoot and hallux and thus could impact upon ulcer healing/recurrence rates [27], therefore the impact of post-operative management should have been discussed in the studies. While most of the studies employed some form of footwear offloading, protocols are only briefly discussed and are not sufficient to inform robust comparison. It is probable that the provision of offloading footwear itself may have had a confounding influence on outcomes.

The low incidence of adverse events and ulcer recurrence must be interpreted cautiously due to deficiencies in reporting, most notably due to the lack of consistent and rigid patient follow-up protocols. Indeed it is recognised that spontaneous reporting of adverse effects from medical record review is not a sufficiently rigorous method [28]. Given that ulcer recurrence and post-op complications require time to manifest, the follow-up period must be sufficient, standardised across studies, and include all study participants to ensure accurate reporting. No minimum recommended follow-up periods are unequivocally accepted in the wider literature on digital surgery and diabetic ulceration. However, a period of one year has been deemed a reasonable follow-up period based on SIGN [29] guidelines which recommend that patients at high-risk of ulceration are assessed annually by a specialist podiatrist. In the case of the minimum follow up times reported in Rassmussen et al. [15] and Tamir et al. [24] it could be argued that ulcer recurrence and complications were not adequately monitored.

The means of conducting follow up is also vague across the studies. Laborde [17] describe a follow-up protocol using both telephone and in-person follow-up. However, it is unclear as to whether or not telephonebased follow-ups are safe and effective as these would 
likely require a certain level of health literacy amongst patients. In the absence of any reporting by the other authors, the validity of their reported post-operative recurrence and complication rates cannot be determined.

\section{Conclusion}

Favourable short-term results are reported across the studies included in this review, suggesting that the flexor tenotomy may be an effective intervention for achieving toe ulcer healing and preventing ulcer recurrence. However these results should be interpreted with caution due to poor methodological rigour, and lack of appropriate follow-up procedures identified in the studies included in this review and the limited evidence concerning longterm outcomes and post-operative complications. We acknowledge that designing a randomised controlled trial suitable for establishing the efficacy of a surgical intervention is challenging due to inherent ethical issues surrounding experimental surgical interventions. However more high quality research is required to support the use of the flexor tenotomy procedure as a mainstream treatment option for achieving and maintaining digital ulcer healing in people with diabetes and neuropathy.

\section{Additional files}

Additional file 1: Excluded article list. Data Table containing excluded article list. (DOCX 20 kb)

Additional file 2: Final agreed MINORS Evaluation for Non-Comparative Studies. Data Table containing MINORS evaluation. (DOCX 18 kb)

\begin{abstract}
Abbreviations
$A B P I$, ankle brachial pressure index; $C R D$, centre for reviews and dissemination; FDB, flexor digitorum brevis; FDL, flexor digitorum longus; FHB, flexor hallucis brevis; FHL, flexor hallucis longus; MINORS, methodological index for nonrandomised studies; No., number; PAD, peripheral arterial disease; PRISMA preferred reporting items for systematic reviews and meta-analyses; SIGN,
\end{abstract} Scottish intercollegiate guidelines network; UT, University of Texas

\section{Funding}

None.

\section{Availability of data and materials}

The datasets supporting the conclusions of this article is are included within this article's additional files.

\section{Authors' contributions}

$J S$ and $J L$ conceived the study. JS performed the literature search and extracted the data with guidance from GJH and JL. JS and GJH independently reviewed all eligible studies and $J L$ resolved any disagreements in scoring. JS drafted the manuscript and all authors reviewed, redrafted and approved the final manuscript.

\section{Competing interests}

The authors declare that they have no competing interests.

\section{Consent for publication}

Not applicable.

Ethics approval and consent to participate Not applicable.
Received: 27 April 2016 Accepted: 26 July 2016

Published online: 29 July 2016

\section{References}

1. Gershater MA, Londahl M, Nyberg P, Larsson J, Thorne J, Eneroth M, et al. Complexity of factors related to outcome of neuropathic and neuroischemic/ischaemic diabetic foot ulcers: a cohort study. Diabetologia. 2009;52:398-407.

2. Ince $P$, Kendrick D, Game $F$, Jeffcoate $W$. The association between baseline characteristics and the outcome of foot lesions in a UK population with diabetes. Diabet Med. 2007;24:977-81.

3. Pickwell K, Siersma VD, Kars M, et al. Diabetic foot disease: impact of ulcer location on ulcer healing. Diabetes Metab Res Rev. 2010;29:337-83.

4. Isakov E, Budoragin N, Shenhav S, Mendelevich I, Korzets A, Susak Z. Anatomic sites of foot lesions resulting in amputation among diabetics and non-diabetics. Am J Phys Med Rehab. 1995;74(2):130-3.

5. Cowley M, Boyko EJ, Shofer JB, Ahroni JH, Ledoux WR. Foot ulcer risk and location in relation to prospective clinical assessment of foot shape and mobility among persons with diabetes. Diabetes Res Clin Pract. 2008;82: 226-32.

6. La Fontaine J, Lavery LA, Hunt NA, Murdoch DP. The role of surgical off-loading to prevent recurrent ulcerations. Int J Low Extrem Wounds. 2014;13:320-34.

7. Raspovic A, Landorf KB, Gazarek J, Stark M. Reduction of peak plantar pressure in people with diabetes-related peripheral neuropathy: an evaluation of the DH pressure relief Shoe ${ }^{\mathrm{TM}}$. J Foot Ankle Res. 2012;5:25.

8. Roukis TS, Schade VL. Percutaneous flexor tenotomy for treatment of neuropathic toe ulceration secondary to toe contracture in persons with diabetes: a systematic review. J Foot Ankle Surg. 2009;48:684-9.

9. Cavanagh PR, Lipsky BA, Bradbury AW, Botek G. Treatment for diabetic foot ulcers. Lancet. 2005;366:1725-35.

10. Bus SA. Priorities in offloading the diabetic foot. Diabetes Metab Res Rev. 2012;28 Suppl 1:54-9.

11. Bus SA, Valk GD, van Deursen RW, Armstrong DG, Caravaggi C, Hlavacek P, et al. The effectiveness of footwear and offloading interventions to prevent and heal foot ulcers and reduce plantar pressure in diabetes: a systematic review. Diabetes Metab Res Rev. 2008;24 Suppl 1:162-80.

12. Frykberg RG, Bevilacqua NJ, Habershaw G. Surgical offloading of the diabetic foot. J Vasc Surg. 2010;52:44S-58S.

13. Landsman A, Cook E, Cook J. Tenotomy and tendon transfer about the forefoot, midfoot and hindfoot. Clin Podiatr Med Surg. 2008;25:547-69.

14. Schepers T, Berendsen HA, Hok Oei I, Koning J. Functional outcome and patient satisfaction after flexor tenotomy for plantar ulcers of the toes. J Foot Ankle Surg. 2010;49:119-22.

15. Rasmussen A, Bjerre-Christensen U, Almdal TP, Holstein P. Percutaneous flexor tenotomy for preventing and treating toe ulcers in people with diabetes mellitus. J Tissue Viability. 2013;22:68-73.

16. Tamir E, McLaren A, Gadgil A, Daniels TR. Outpatient percutaneous flexor tenotomies for management of diabetic claw toe deformities with ulcers: a preliminary report. Can J Surg. 2008:51:41-4.

17. Laborde JM. Neuropathic toe ulcers treated with toe flexor tenotomies. Foot Ankle Int. 2007;28:1160-4.

18. Pollard JP, Morrison PJ. Flexor tenotomy in the treatment of curly toes. Proc R Soc Med. 1975;68:480-1.

19. Centre for Reviews and Dissemination. Systematic reviews: CRD's guidance for undertaking reviews in health care. York: CRD; 2009.

20. Slim K, Nini E, Forestier D, Kwiatkowski F, Panis Y, Chipponi J. Methodological index for Non-randomized studies (MINORS): development and validation of a new instrument. ANZ J Surg. 2003;73:712-6.

21. Fitzpatrick-Lewis D, Ciliska D, Thomas H. The methods for the synthesis of studies without control groups, National collaborating centre for methods and tools. Hamilton: National Collaborating Centre for Methods and Tools; 2009.

22. Oxford Centre for Evidence-based Medicine. Levels of Evidence (March 2009). http://www.cebm.net/oxford-centre-evidence-based-medicine-levels-evidencemarch-2009/. Accessed 11 Apr 2016

23. Kearney TP, Hunt NA, Lavery LA. Safety and effectiveness of flexor tenotomies to heal toe ulcers in persons with diabetes. Diabetes Res Clin Pract. 2010;89:224-6.

24. Tamir E, Vigler M, Avisar E, Finestone AS. Percutaneous tenotomy for the treatment of diabetic toe ulcers. Foot Ankle Int. 2014;35:38-43. 
25. Van Netten JJ, Bril A, van Baal JG. The effect of flexor tenotomy on healing and prevention of neuropathic diabetic foot ulcers on the distal end of the toe. J Foot Ankle Res. 2013;6:3.

26. Oyibo S, Jude EB, Tarawneh I, Nguyen HC, Harkless LB, Boulton AJM. A Comparison of two diabetic foot ulcer classification systems. Diabetes Care. 2001;24:84-8.

27. Kavros SJ, Van Straaten MG, Coleman Wood KA, Kaufman KR. Forefoot plantar pressure reduction of off-the-shelf rocker bottom provisional footwear. Clin Biomech. 2011;26:778-82.

28. Loke YK, Price D, Herxheimer A. Systematic reviews of adverse effects: framework for a structured approach. BMC Med Res Methodol. 2007;7:32

29. Scottish Intercollegiate Guidelines Network (SIGN). Guideline 116: Management of Diabetes. Available at: http://www.sign.ac.uk/guidelines/fulltext/116. Accessed 05 Mar 2015.

30. Moher D, Liberati A, Tetzlaff J, Altman DG. Preferred reporting items for systematic reviews and meta-analyses: the PRISMA statement. BMJ 2009:339:332-6

Submit your next manuscript to BioMed Central and we will help you at every step:

- We accept pre-submission inquiries

- Our selector tool helps you to find the most relevant journal

- We provide round the clock customer support

- Convenient online submission

- Thorough peer review

- Inclusion in PubMed and all major indexing services

- Maximum visibility for your research

Submit your manuscript at www.biomedcentral.com/submit
Biomed Central 